\title{
Strategic management of pediatric intensive care unit in a tertiary children's hospital in southwest China during the COVID-19 pandemic
}

\author{
Ping Zeng ${ }^{1 \#}$, Xiaoli Luo ${ }^{1 \#}$, Wen Zeng ${ }^{2}$, Dan Qiu ${ }^{1}$, Ling Zhang ${ }^{1}$, Qin Zhou ${ }^{1}$, Tao Wang ${ }^{1}$, Zihong Xiong ${ }^{1}$ \\ ${ }^{1}$ Department of Pediatric Critical Medicine, Chengdu Women's and Children's Central Hospital, School of Medicine, University of Electronic \\ Science and Technology of China, Chengdu, China; ${ }^{2}$ Department of Neonatology, Chengdu Women's and Children's Central Hospital, School of \\ Medicine, University of Electronic Science and Technology of China, Chengdu, China \\ \#These authors contributed equally to this work. \\ Correspondence to: Xiaoli Luo. Department of Pediatric Critical Medicine, Chengdu Women's and Children's Central Hospital, School of Medicine, \\ University of Electronic Science and Technology of China, Chengdu, China. Email: 55050625@qq.com.
}

\begin{abstract}
Since early December 2019, patients with unknown pneumonia have been found in Wuhan City, Hubei Province, China. The pathogen in these cases was quickly identified as a new type of coronavirus. The World Health Organization named it 2019 novel coronavirus (2019-nCoV), and the disease caused by the pathogen was called 2019 Coronavirus Disease (COVID-19), which was characterized by higher pathogenicity, transmission of human to human. So it has rapidly spread to more than 190 countries all over the world. With the sudden outbreak of COVID-19, preventing the spread of COVID-19 is the primary problem. Despite fewer children than adults have been affected by the COVID-19, Pediatric Intensive Care Unit (PICU), as a ward for critically ill patients, is also confronted with high risk of 2019-nCoV infection. It is necessary for PICU managers to thoroughly carry out scientific and effective department management and carefully execute of infection control measures to prevent the transmission. According to recommendations for the COVID-19 prevention and control, the relevant guidelines and the authors' work experience, this paper proposes and optimizes the strategic plan for the management of COVID-19 outbreak in PICU, and emphasizes that department managers should conduct comprehensive risk assessments, manage the pediatric patients and healthcare workers meticulously, strengthen the implementation of infection control measures, and use risk management and process control to effectively manage the department as well as to protect the safety of both the patients and the staff.
\end{abstract}

Keywords: Coronavirus disease 2019 (COVID-19); 2019 novel coronavirus(2019-nCoV); management; prevention; pediatric intensive care unit (PICU)

Submitted Oct 30, 2020. Accepted for publication Dec 16, 2020.

doi: $10.21037 /$ tp-20-422

View this article at: http://dx.doi.org/10.21037/tp-20-422

\section{Introduction}

In December 2019, a number of pneumonia cases of unknown cause with fever as the first symptom appeared in Wuhan, Hubei, China (1-3). The disease proceeded to spread rapidly all over the country and the world. So far, data from Johns Hopkins University shows that as of 10:00,
November 26, Eastern Standard Time, there have been a total of 60,541,397 confirmed cases of and 1,424,224 deaths resulting from coronavirus disease 2019 (COVID-19) in 191 countries and regions in the world, with a mortality rate close to $2.35 \%$ (4). This shows that COVID-19 is a global disease with strong pathogenicity, high infectivity and high

^ ORCID: Xiaoli Luo, 0000-0002-0002-944X; Wen Zeng, 0000-0002-8064-3203. 
mortality, During the early stage of the pandemic, based on outbreak intervention and monitoring by China's health care and public health institutions since December 2019, the Chinese Center for Disease Control and Prevention (CDC) officially announced on January 7, 2020 that the cause of the outbreak was a new strain of coronavirus that had never been found in the human body before (5). On January 12, the World Health Organization (WHO) named the virus 2019-nCoV (6). On February 11, 2020, WHO announced the name of the disease caused by the novel coronavirus as COVID-19 (7). Currently in China, COVID-19 is classified as a category $\mathrm{B}$ communicable disease as defined under the Infectious Disease Prevention and Control Law, and managed by using the prevention and control measures for category A communicable diseases. It is now known that the population in general is susceptible to the virus, and its routes of transmission are mainly respiratory droplets, contact, and aerosol in special environments (8).

Following the national novel coronavirus infection control and prevention requirements and the public health emergency management regulations, Chinese medical institutions have been conducting pre-triage management of outpatients and emergency department (ED) patients to effectively isolate COVID-19 patients, thereby suppressing transmission. At present, the novel coronavirus has been effectively controlled in China, but the number of imported cases has been gradually increasing, and China is still facing a grave situation.

As a critical medicine department is the place of treatment for critically ill patients who typically experience acute disease onset, rapid disease progress, and many invasive operations, proper departmental management is vital to ensure the safety of both patients and medical staff, and to control the spread of the pandemic. Children, as a special group with relatively low immune functions, require an even higher standard of management. Our hospital is a women's and children's health care institution integrating clinical work, research, and teaching with 1,657 beds. It is a leading hospital in China's southwest in terms of both the volume of obstetrics/gynecology (OB/GYN) and pediatric conditions being diagnosed and treated and the level of in-house clinical expertise. Our department was one of the earliest integrated pediatric intensive care unit (PICU) established in the Sichuan Province. It is the provincial emergency and transfer center for children with critical illness and has 40 beds. Based on the epidemic characteristics of COVID-19 in Southwest China, the clinical characteristics of PICU cases, and through literatures review and summary of our own management experience, this paper aims to provide information and insights on the management of PICUs in the COVID-19 era. We propose the PICU workflow during the pandemic, focusing on the management of critically ill children and their families, the management of subarea and color in the ward, infection control and disinfection management in the hospital, staff training, mental health under work pressure, emphasizing the importance of nosocomial infection control and disinfection. The managers of PICU should have the awareness of risk prevention and pay attention to the mental health of staff under strong pressure. Swapna et al. from national university hospital, Singapore also emphasized that strategies need to be put in PICU to prevent further spread of the virus and present a summary of the general measures implemented at a large adult and pediatric hospital in Singapore. In particular, simulation training has been conducted within the PICU for emergency airway management for COVID-19 patients. Meanwhile, they have implemented the use of an intubation checklist (9). Sarman et al. from Bingol University, Turkey put forward that in PICU it should be provided childfriendly, family-centered, and child centered care procedures to promote family unity and reduce the risk of separation anxiety and the establishment of mental health expert nursing teams, psychological counseling may have helped prevent negative mental health of COVID-19 outcomes (10). This shows that psychological intervention plays an important role not only for patients and their families, but also for the health of medical staff.

\section{Management of pediatric patients}

\section{Additional screening before admission}

Even though the population as a whole is susceptible to the novel coronavirus, the infection rate is relatively low among children. Dong et al. found that from January 16, 2020 to February 8, 2020, a total of 2,135 pediatric COVID-19 cases were reported to the Chinese CDC nationwide, and 728 (34.1\%) of them were laboratory-confirmed cases (11). The median age of these patients was 7 years. More than $90 \%$ of this whole group of patients were asymptomatic, mild, or moderate cases. Lu et al. also reported that most infected children appeared to have a milder clinical course and asymptomatic infections were not uncommon in contrast with infected adults (12). A total of 27 patients (15.8\%) did not have any symptoms of infection or radiologic features of pneumonia. The US CDC analyzed data from 149,760 
laboratory-confirmed COVID-19 cases in the US occurring between February 12 and April 2, 2020, and found that among 149,082 (99.6\%) reported cases for which age was known, 2,572 (1.7\%) were children aged $<18$ years, and a total of 3 deaths were reported among the pediatric cases included in their analysis (13). Most of the pediatric cases have a family history of infection, and clustering has been the prominent feature of the outbreak among children (14-16). Cases of confirmed infection have been reported in children of all ages. Although most of these cases have had a history of close contact and family clustering, it has been found that some children and newborns displayed atypical symptoms including transient fever and short heat range without prominent respiratory tract symptoms. Instead, they have presented with vomiting, diarrhea, and other digestive tract symptoms, which has posed severe challenges to the early identification of the disease, as it is very difficult for clinicians to distinguish these cases from other diseases. When suspected pediatric COVID-19 cases are not prescreened in the outpatient clinic or ED, the children end up being rushed to the PICU due to their critical conditions. Due to this concern, we have treated every newly admitted child with great caution during this outbreak. We check the temperature of the child and his/her family, and ask about his/her epidemiology history before admitting the child into the PICU. We also require the family to sign an informed consent form and acknowledge the legal repercussions of providing false information.

\section{Separate zones after admission}

In response to the COVID-19 outbreak, we have readjusted the PICU layout. The original area for treating infectious disease was changed to a "Zone for the Newly Admitted" ("New Zone" hereafter), specifically dedicated to treating newly admitted patients. This area includes two negative pressure wards. The original area for treating non-infectious diseases was changed to a "Zone for Stable Patients" ("Stable Zone" hereafter), dedicated to treating conventional PICU patients. The two areas have completely separated ventilation systems. Of course, if the conditions of a PICU do not allow adjustments like those mentioned above, a relatively independent "Isolation Area" can be set up to separate the new patients from other conventional patients to prevent cross infection. Each new patient is admitted to the New Zone and managed in a single room. Clinicians check the epidemiology history, clinical symptoms and vital signs, and order lab work, imaging, and other relevant examinations within 48-72 hours of admission. We have implemented a system of asking 5 questions and performing 5 checks (17). The 5 questions relate to the patient's epidemiological history within the last 14 days; they are: (I) Have the child and his/her parents (guardians) ever been to any outbreak area (or Wuhan during the early state of the pandemic) or its surrounding areas? (II) Have the child and his/her parents (guardians) had any contact with people from any outbreak area (or Wuhan at the early stage of the pandemic) or its surrounding areas? (III) Has there been any contact with people infected with the novel coronavirus (i.e., with positive nucleic acid test) recently? (IV) Have there been any confirmed COVID-19 patients in your community or residential area? (V) Has there been anybody with fever or respiratory symptoms in close proximity to you? Epidemiological history is of particular importance for pediatric patients, especially those outside Hubei, and even asymptomatic children with a history of close contact with confirmed or suspected cases have to be screened. The 5 checks are as follows: (I) check the body temperature; (II) ask about respiratory symptoms and check lung signs for phlegm sounds, dry and/or wet rales, dyspnea, cyanosis, etc.; (III) check the routine blood test for whether the white blood cells and lymphocytes are normal or decreased, and whether the C-reactive protein is normal or increased; (IV) check the chest imaging. For a patient with respiratory tract infection without an epidemiological history, especially an older child with persistent fever or signs of pulmonary infection, a high-resolution computed tomography (CT) scan of the lung needs to be performed in addition to checking for other pathogens such as influenza virus, mycoplasma, etc.; (V) check the nucleic acid test. The patient can only be transferred from New Zone to the Stable Zone after their swab results of $2019-\mathrm{nCoV}$ nucleic acid test is negative and the possibility of coronavirus infection has been eliminated. If the clinician highly suspects coronavirus infection, the child will be immediately transferred to the negative pressure ward for isolation, and the case reported to senior staff following an established protocol. If a higher-level clinician cannot rule out the infection, the hospital's expert consultation mechanism will be initiated. See the flow chart for new patient treatment (Figure 1).

\section{Monitoring of symptoms and vital signs during bospitalization}

Following hospitalization, a child's temperature is 


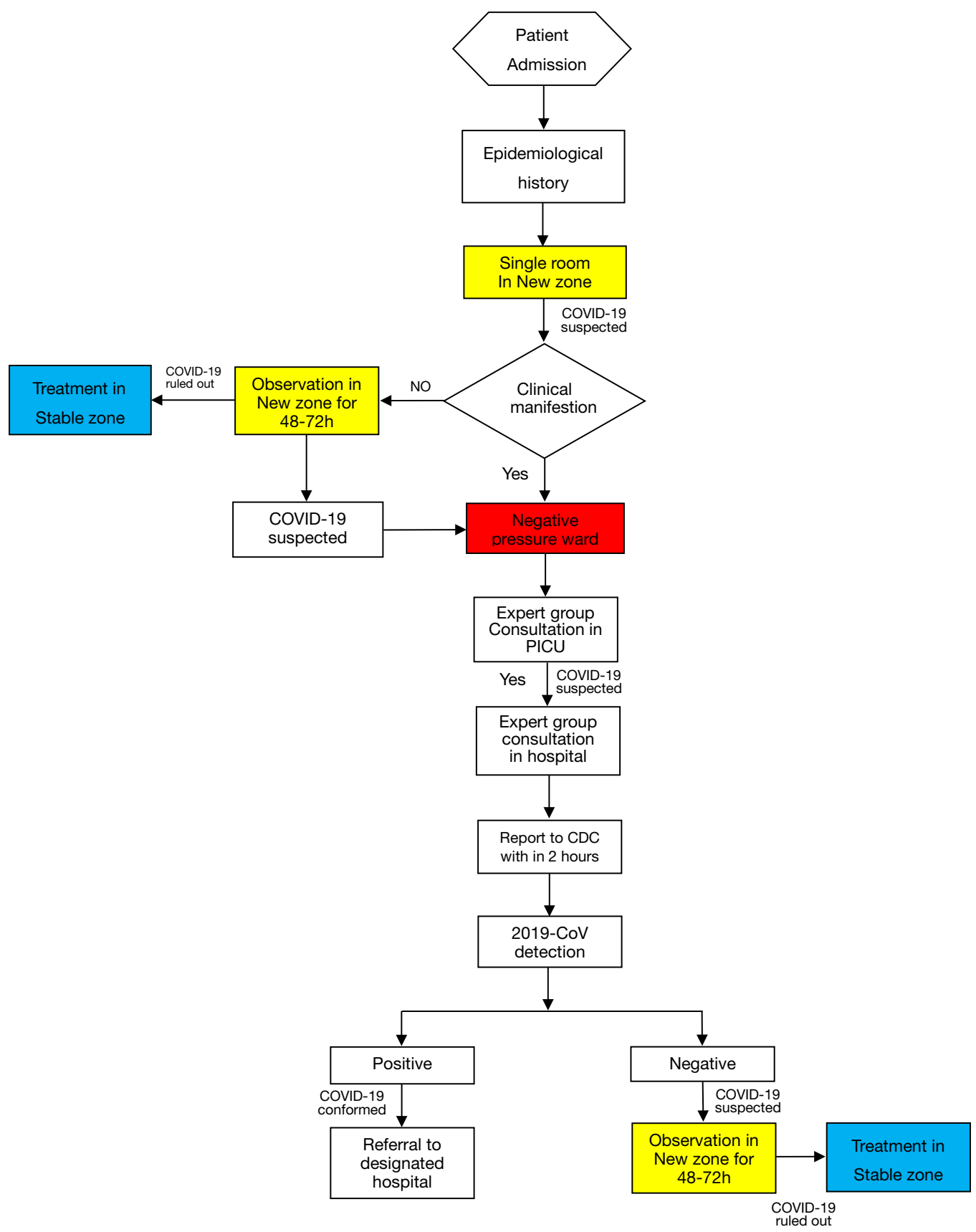

Figure 1 PICU COVID-19 patient screening and management. PICU, pediatric intensive care unit; COVID-19, coronavirus disease 2019.

taken and symptoms (including fever, tremor, fatigue, headache, muscle-joint pain, cough, runny nose, vomiting, diarrhea and state of mental and appetite etc.) and vital signs (including temperature, pulse, respiration rate, blood pressure) are monitored daily according to the standard routine. If a child is found to have a fever (body temperature $\geq 37.3{ }^{\circ} \mathrm{C}$ or $99.14{ }^{\circ} \mathrm{F}$ ), a mercury thermometer or ear temperature gun is used to repeat the test. If the temperature reading is still $\geq 37.3{ }^{\circ} \mathrm{C}$ or $99.14{ }^{\circ} \mathrm{F}$, the epidemiology or congregation history is asked again to assist the doctor in completing the laboratory and imaging studies. If suspicion of coronavirus infection is high, the patient will be transferred immediately to the negative pressure ward for isolation and treatment. 


\section{Health education}

Education for the prevention of COVID-19 is important in addition to treatment. Wang et al.'s direct observation of caregivers during the coronavirus outbreak showed that $84.62 \%$ of the people were following the requirement to wear masks, but only $50.57 \%$ wore the masks correctly; $75.00 \%$ of the people were practicing hand hygiene, but only $22.44 \%$ were doing it correctly, suggesting that prevention awareness and hand hygiene practices were poor among caregivers (18). If caregivers do not protect themselves adequately, the coronavirus could be directly transmitted to both patients and medical staff. In addition to face-to-face prevention education, we also have been educating the elder children and their caregivers on how to wear masks correctly, follow etiquettes for coughing and sneezing, maintain satisfactory hand hygiene, and other methods of personal protection through relevant updated information on TV and distribution of leaflets. We also have been limiting the time that caregivers can remain in the hospital, and emphasizing social distancing; we also inform them that discarded masks are required to be disposed of in designated garbage cans. Additionally, we have been emphasizing to the caregivers the importance and necessity of truthful reporting of their epidemiological history.

\section{Psychological care}

Because the 2019-nCoV is a new and highly infectious virus, and the population overall is susceptible to it, our department has implemented a temporary closed management system, and has suspended caregiver visitations in order to reduce the risk of cross infection. To reduce panic and separation anxiety in the elder children and their parents, we have been monitoring the psychological state of the children closely by conducting timely assessments of their emotional and behavioral changes and providing emotional support. Concurrently, in order to minimize these children's sense of isolation and meet their emotional needs, we encourage them to communicate with their parents through cell phone calls or video chats.

\section{Visitation management}

Caregivers are an important floating population in our hospital, but their awareness of and ability for infection prevention are relatively low. Temporary restriction of visitation reduces hospital population flow, chances of exposure, and the risk of cross infection among caregivers. Such restrictions have been widely adopted during outbreaks of various infectious diseases (19). We have implemented strict access control in the inpatient building. Each child inpatient is given one visitors card, and the card has to be displayed when entering and exiting the inpatient building. In order to reduce unnecessary cross infection, the PICU, as a ward that does not generally allow caregivers to stay overnight, has implemented a closed management system and suspended caregiver visits during the outbreak. For some of the critically ill or dying children, caregivers are allowed visits for humanistic purposes, but the number of visitors and frequency of visits remains limited. Visitors are required to divulge their personal information, consent to investigation of their epidemiological histories, have their body temperature taken and recorded, and diligently follow the instructions for protective measures.

\section{Transfers}

If a new patient needs to leave the PICU for an examination or test, the PICU medical staff will alert the examination or test department in advance so staff there can undertake preventative protection measures. After completion of the examination or test, the relevant department will conduct routine disinfection. When a confirmed or highly suspected patient needs to be transferred to another hospital, the designated hospital will send an ambulance to collect the patient, and it is advised to use a negative pressure stretcher, if available; if not, a common stretcher may be used. The patient is required to wear a medical surgical mask during transport. The transfer personnel are instructed to wear the personal protective equipment (PPE) of medical protective and surgical masks, double-layer gloves, protective and disposable isolation clothing, boot covers, medical caps, and goggles. Security personnel will clear the route before the transfer to prevent infecting others. After the transfer, the stretcher will be sprayed with $2,000 \mathrm{mg} / \mathrm{L}$ chlorine disinfectant for 60 minutes, and then wiped with clean water.

\section{Management of staff}

Staff includes all doctors and nurses, including those visiting or training at our hospital, and cleaning workers and employees assisting the daily care of patients in our hospital. 


\section{Epidemiological bistory screening and self-bealth monitoring}

Department managers should pay great attention to the health of staff, have knowledge of any travel undertaken by staff during the pandemic, report on their own, their family members' and close contacts' travel history or residence in any outbreak area, and perform dynamic staff management. Anybody with an epidemiology history will be quarantined at home for 14 days. After the 14 days, those without COVID-19 symptoms will be released from quarantine and are able to return to work. Our hospital has formulated the "Health Monitoring and Reporting System for Staff during the COVID-19 Outbreak" for real-time dynamic management of staff, who take their own temperatures twice a day. If a medical staff member has a fever or respiratory symptoms, he/she immediately ceases contact with patients, and then proceeds to a general hospital fever clinic after taking protective measures. Medical quarantine or further treatment is conducted according to examination results, which are then promptly reported to the relevant department. If a medical staff member becomes a suspected or confirmed case of COVID-19, he/she is requested to record all recent close contacts; these contacts are placed under medical observation, and other necessary precautionary measures are taken. The relevant information is then immediately reported to the hospital infection control department.

\section{Differentiated training}

During the pandemic, the training of all staff members should be increased to continuously update their knowledge and prevention awareness of COVID-19, as well as enhance their abilities to protect themselves. The training content for different staff should be determined in accordance with their professional responsibilities, but should entail diagnostic and treatment information for COVID-19, technical and operational skills, hospital infection control and prevention, emergency drills, and so on (Table 1). In order to minimize points of contact among staff, we have been using WeChat groups, video conferences, and other methods to enable online training.

\section{Psychological guidance and support}

At present, there is no large-scale epidemiological data delineating the main psychological problems caused by the pandemic, or the main psychological problems in different groups of people. Numerous research and crisis intervention experiences have suggested that COVID-19 is a highly stressful event for health care workers, contributing to an array of physical and psychological conditions (20). In such a state of stress, people tend to lose their internal balance, and become susceptible to experiencing tension, fear, worry, anxiety, and insomnia, in addition to a variety of physical problems. Yang et al. found that there was a very strong demand for psychological support among the first cohort of nurses at the Covid-19 front line as the intensity of workplace pressure mounted with the pandemic (21). Nursing managers are therefore advised to monitor the psychological pressure experienced by their nurses, and offer help and guidance to support their mental health. Yu et al. reported that post-traumatic stress from long term traumas has a negative impact on work efficiency and social functioning, and can seriously affect the physical and mental health of those afflicted (22). Therefore, timely and effective psychological crisis interventions are vital. Our hospital has been conducting psychological tests for all staff members in order to understand their psychological needs and formulate psychological intervention plans, particularly for the clinical frontline staff. We have also recruited qualified psychological consultants and assigned each of them to several departments for in-person counseling. The psychological counselors collaborate with the relevant hospital department managers in order to offer support to the affected staff.

\section{Management of other staff members}

In order to ensure the safety of interns throughout the pandemic, the management of all interns has been entrusted to the medical school itself. At the same time, we have paid special attention to the management of workers performing cleaning duties or assisting with everyday living of patients in the department. This demographic of employees are typically not well educated, and have experienced more fear and anxiety about COVID-19. In addition to offering psychological support, we have trained them on the correct use of PPE, and have been ensuring that disinfection and isolation as well as medical waste collection and transfer are performed properly so that these groups of workers are protected.

\section{Human resource management}

An emergency COVID-19 human resource deployment 
Table 1 Personalized training programs for different employees

\begin{tabular}{|c|c|c|c|c|}
\hline Training projects & Training content & \multicolumn{3}{|c|}{ Trainees } \\
\hline \multicolumn{5}{|l|}{ Theoretical training } \\
\hline \multirow{2}{*}{$\begin{array}{l}\text { COVID-19 related } \\
\text { medical knowledge }\end{array}$} & Epidemic trend, epidemiological history & $\bullet$ & $\boldsymbol{\Delta}$ & $\triangle$ \\
\hline & Diagnostic criteria, treatment plan, diagnostic consultation process & $\bullet$ & $\boldsymbol{\Delta}$ & $\triangle$ \\
\hline \multicolumn{5}{|l|}{ Practical skills training } \\
\hline \multirow[t]{2}{*}{ Protection skills } & $\begin{array}{l}\text { How to use PPE correctly (masks, hats, gloves, shoe covers, goggles, protective } \\
\text { clothing, positive pressure headgear) }\end{array}$ & $\bullet$ & $\bullet$ & $\circ$ \\
\hline & PPE accident handling (PPE falling off or damaged, PPE fogging) & $\bullet$ & $\bullet$ & $\circ$ \\
\hline \multirow{3}{*}{$\begin{array}{l}\text { Infection control } \\
\text { related information }\end{array}$} & Configuration and placement of disinfectant in different areas & $\circ$ & $\circ$ & $\bullet$ \\
\hline & Standardized disposal of medical wastes & $\circ$ & $\circ$ & $\bullet$ \\
\hline & Disposal of blood, body fluids, and vomit of confirmed/suspected patients & $\bullet$ & • & $\bullet$ \\
\hline \multirow[t]{3}{*}{$\begin{array}{l}\text { Work system and } \\
\text { SOPs }\end{array}$} & $\begin{array}{l}\text { Guidelines for PPE use in different environments (clinical, auxiliary, administrative } \\
\text { and logistics, and cleaning departments) }\end{array}$ & $\bullet$ & $\bullet$ & $\triangle$ \\
\hline & Emergency treatment process for COVID-19 patients mistakenly admitted & $\bullet$ & $\bullet$ & $\circ$ \\
\hline & Transfer process within hospital & $\bullet$ & $\bullet$ & $\triangle$ \\
\hline
\end{tabular}

$\bullet$, need to master; $\boldsymbol{\Delta}$, need to be familiar with; $\circ$, need to understand; $\triangle$, no need to know. COVID-19, coronavirus disease 2019; PPE, personal protective equipment; SOP, standard operating procedure.

plan needs to be constructed and implemented based on the principles of comprehensive management, dynamic adjustment, satisfaction of needs, safety assurance, and efficiency. Our department works closely with the entire hospital in the overall deployment of staff. The first priority is to ensure that important posts are staffed; we have also made an echelon plan to ensure that the human resource needs of clinical routine and outbreak response work are met, and the deployment and use of human resources are efficient. The New and Stable Zones are staffed based on the number of hospitalized children and the workload, and every effort is made to ensure that while the priority of clinical safety is realized as much as possible, the number of people reporting to work and the use of personal protection equipment (PPE) are economically managed.

\section{Ward and PPE management}

\section{Color system}

As mentioned before, we have adapted the layout of the department in response to the pandemic. Specifically, the patient area has been divided into the New and Stable Zones, and these two areas have independent ventilation systems. Concurrently, we have set up one admission and two discharge routes. All newly admitted children enter the New Zone through the admission route, and each of 
them is allocated to a single room; they are then triaged based on the results of screening. The No. 1 discharge route is located within the New Zone. Originally the waste disposal access, it is now used for the discharge of likely or confirmed COVID-19 patients. The No. 2 discharge route is for routine PICU patients, is located within the Stable Zone, and is the conversion of the original postoperative patient discharge route. The two discharge routes are completely physically separated to prevent cross infection. Color management has been added to the above mentioned area divisions to achieve target management of different areas: the two negative pressure wards have become the red area, while the New Zone and admission access areas have become the yellow area. The blue area includes the Stable Zone, warehouse, and catering room, and the green area is the old rest area for staff and the conference room. After the changes were implemented, we used the corresponding colors to make the physical partition boundary on the floor (Figure 2). The staff follow the tiered protection measures according to the areas they are entering (Table 2).

\section{Access control management}

After we implemented the above temporary alterations to the original admission and discharge routes, we set up physical barriers along the adjusted routes to prevent people from going the wrong way. We have also erected special signs to direct patients and their caregivers to go separate ways from the medical staff. Access control has been established in all medical areas, and personnel dedicated to body temperature monitoring and recording of the coming and goings of caregivers have been stationed at the entrances of the ward.

\section{PPE management}

In order to prevent a shortage PPE, our department has been subject to the centralized supply management of the hospital, which distributes PPEs based on the number of patients, type of diseases, risks of exposure, and staff composition of each department. The PPEs, once received by us, are wiped with $75 \%$ alcohol or sprayed with $500 \mathrm{mg} /$ $\mathrm{L}$ chlorine containing disinfectant before being allowed into the department. To provide medical staff with adequate protection while also minimizing PPE waste, diagnostic and treatment activities are carried out in different areas of the ward in accordance with the tied protection requirements.

\section{Hospital infection and disinfection management}

The novel coronavirus belongs to the group of beta genus coronaviruses. The virus is sensitive to ultraviolet and heat. It can be effectively inactivated at $56^{\circ} \mathrm{C}$ (or $132.8^{\circ} \mathrm{F}$ ) for 30 minutes, or with ether $75 \%$ ethanol, chlorine disinfectant, peracetic acid, or chloroform. During the pandemic, we disinfect the blue and green areas in accordance with the 2012 National Technical Code for Disinfection of Medical Institutions (23), and the red and yellow areas according to the National Prevention and Control Plan for the Novel Coronavirus Induced Pneumonia (the 3rd Edition) (24). To assist the cleaners and medical staff follow the rules, we have made a table listing different disinfection methods, printed them out, and hung them conspicuously in various places (Table 3).

\section{Disinfection of floors and walls}

In our hospital, when pollutants are visible to the naked eye, they must be completely removed with hygroscopic materials prior to disinfection. For ground disinfection, disinfectant containing chlorine is sprayed from the outside perimeter to the inside once. Disinfection time should be $\geq 30$ minutes. Afterwards, the floor is cleaned with water again. This process is repeated $\geq 2$ times a day.

\section{Ambient air disinfection}

Terminal disinfection of ambient air is carried out in accordance with the Management Standard for Hospital Air Purification (25). Disinfectants such as peracetic acid, chlorine dioxide, and hydrogen peroxide may be used under unmanned conditions, and disinfection is performed through an ultra-low volume spray method. Our department is a laminar flow ward, so we monitor the air and clean and disinfect the filter screens regularly. We ventilate the office and rest areas, and open the windows as much as possible in more heavily frequented areas; and we disinfect the air with an air disinfector once a day for $\geq 30$ minutes each time (26).

\section{Disinfection of clothing and bedding}

The collection of contaminated clothing and bedding should be performed gently to prevent the formation of aerosols. When conducting terminal treatment of these items, if there are no visible pollutants, a bed unit sterilizer can be 


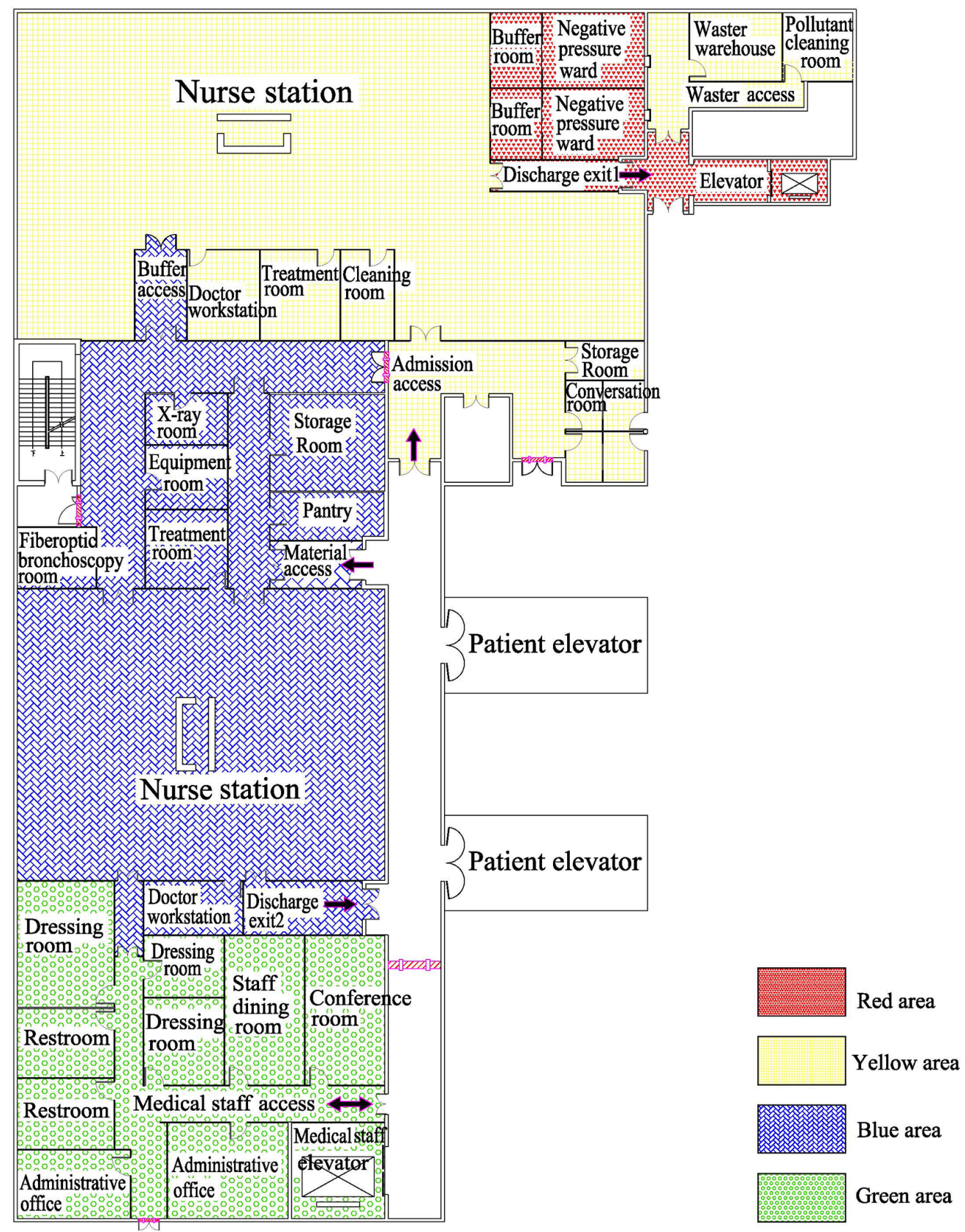

Figure 2 PICU ward layout and the color system. PICU, pediatric intensive care unit.

used to sterilize the bedding, pillows, and mattress (27). Clothing of suspected or confirmed patients should be disposed of wherever possible. If they reuse is essential, we pack them in double-layer yellow garbage bags and label them with "new coronavirus infected" on the outside of the bags. We then seal the bags and disinfect them before routine treatment, or use the ethylene oxide method.

\section{Disinfection of instruments and equipment}

We use disposable medical supplies as much as possible in conducting diagnosis and treatment. Nondisposable items such as stethoscopes, thermometers, and sphygmomanometers are sterilized by pressurized steam. Medical devices and nursing supplies are for dedicated 
Table 2 Tiered protection standards for different areas

\begin{tabular}{|c|c|c|c|c|c|c|c|c|c|c|c|c|c|}
\hline Area & Category & $\begin{array}{l}\text { Surgical } \\
\text { mask }\end{array}$ & $\begin{array}{l}\text { N95 } \\
\text { mask }\end{array}$ & Hat & Goggles & $\begin{array}{l}\text { Sterile } \\
\text { rubber } \\
\text { gloves }\end{array}$ & $\begin{array}{c}\text { Protective } \\
\text { face } \\
\text { screen }\end{array}$ & Overall & $\begin{array}{l}\text { Isolation } \\
\text { gown }\end{array}$ & $\begin{array}{l}\text { Protective } \\
\text { clothing }\end{array}$ & $\begin{array}{l}\text { Shoe } \\
\text { covers }\end{array}$ & $\begin{array}{c}\text { Waterproof } \\
\text { boots }\end{array}$ & $\begin{array}{l}\text { Positive } \\
\text { pressure } \\
\text { headgear }\end{array}$ \\
\hline $\begin{array}{l}\text { Green } \\
\text { area }\end{array}$ & $\begin{array}{c}\text { General } \\
\text { protection }\end{array}$ & ० & & 0 & & & & $\bullet$ & & & & & \\
\hline $\begin{array}{l}\text { Blue } \\
\text { area }\end{array}$ & $\begin{array}{c}\text { First tier } \\
\text { protection }\end{array}$ & $\bullet$ & & $\bullet$ & ० & $\bullet$ & ० & $\bullet$ & $\circ$ & & & & \\
\hline $\begin{array}{l}\text { Yellow } \\
\text { area }\end{array}$ & $\begin{array}{c}\text { Second tier } \\
\text { protection }\end{array}$ & o & $\bullet$ & $\bullet$ & $\bullet$ & $\bullet$ & $\bullet$ & $\bullet$ & $\bullet$ & ० & $\bullet$ & & \\
\hline $\begin{array}{l}\text { Red } \\
\text { area }\end{array}$ & $\begin{array}{l}\text { Third tier } \\
\text { protection }\end{array}$ & $\bullet$ & $\bullet$ & $\bullet$ & $\bullet$ & $\bullet$ & $\bullet$ & $\bullet$ & $\circ$ & $\bullet$ & & $\bullet$ & $\circ$ \\
\hline
\end{tabular}

•, need to master; o, need to understand.

Table 3 COVID-19 related disinfection methods for employee reference

\begin{tabular}{|c|c|c|c|}
\hline $\begin{array}{l}\text { Objects of } \\
\text { disinfection }\end{array}$ & Green \& blue areas & Red \&yellow areas & Disinfection instructions \\
\hline Ambient air & Air disinfector & $\begin{array}{l}\text { Peracetic acid, hydrogen } \\
\text { peroxide }\end{array}$ & Spray method \\
\hline $\begin{array}{l}\text { Patient } \\
\text { excrement, } \\
\text { vomit and } \\
\text { secretion }\end{array}$ & $\begin{array}{l}\text { Disinfectant containing } \\
\text { chlorine (400-700 mg/L) }\end{array}$ & $\begin{array}{l}\text { Disinfectant containing } \\
\text { chlorine }(5,000-10,000 \mathrm{mg} / \mathrm{L})\end{array}$ & $\begin{array}{l}\text { Small amounts of pollutants can be removed by using } \\
\text { disposable absorbent materials. Large amounts of pollutants } \\
\text { should be completely covered with disinfectant or bleaching } \\
\text { powder containing absorbent ingredients, followed by } \\
\text { careful removal. Pollutants in the red \& yellow areas should } \\
\text { be collected in special containers, and disposed of after using } \\
\text { a disinfectant containing } 20,000 \mathrm{mg} / \mathrm{L} \text { chlorine, at a fecal to } \\
\text { disinfectant ratio of } 1: 2 \text { for } 2 \text { hours }\end{array}$ \\
\hline $\begin{array}{l}\text { Floors, } \\
\text { walls, } \\
\text { elevators }\end{array}$ & $\begin{array}{l}\text { Disinfectant containing } \\
\text { chlorine }(400-700 \mathrm{mg} / \mathrm{L})\end{array}$ & $\begin{array}{l}\text { Disinfectant containing } \\
\text { chlorine }(1,000 \mathrm{mg} / \mathrm{L}) \text { or } \\
\text { chlorine dioxide }(500 \mathrm{mg} / \mathrm{L})\end{array}$ & $\begin{array}{l}\text { Wipe and spray from the outside to the inside and then from } \\
\text { the inside to the outside for } \geq 30 \text { minutes }\end{array}$ \\
\hline Corpses & Rinse skin with water & $\begin{array}{l}\text { Disinfectant containing } \\
\text { chlorine }(3,000-5,000 \mathrm{mg} / \mathrm{L}) \\
\text { or } 0.5 \% \text { peracetic acid }\end{array}$ & $\begin{array}{l}\text { Fill the open lumen of a corpse with cotton balls or gauze } \\
\text { containing chlorine-based disinfectant }\end{array}$ \\
\hline $\begin{array}{l}\text { Bedclothes } \\
\text { and other } \\
\text { fabrics }\end{array}$ & $\begin{array}{l}\text { Disinfectant containing } \\
\text { chlorine }(250-500 \mathrm{mg} / \mathrm{L}) \\
\text { or chlorine dioxide } \\
(100-250 \mathrm{mg} / \mathrm{L})\end{array}$ & $\begin{array}{l}\text { Disinfectant containing } \\
\text { chlorine }(500 \mathrm{mg} / \mathrm{L})\end{array}$ & $\begin{array}{l}\text { Burn the textiles associated with suspected/confirmed cases } \\
\text { per centralized incineration of medical waste. If reuse is } \\
\text { necessary, soak and disinfect them with } 500 \mathrm{mg} / \mathrm{L} \text { disinfectant } \\
\text { containing chlorine before handling them as usual }\end{array}$ \\
\hline
\end{tabular}

COVID-19, coronavirus disease 2019. 
individual use. For the disinfection or sterilization of nonheat resistant items, chemical disinfectant or low-temperature sterilization equipment are used. Keyboards, mice, walkietalkies, mobile round carts, and other items are wiped with chlorine disinfectant $(500 \mathrm{mg} / \mathrm{L})$ every day, and special personnel are assigned to supervise its implementation.

\section{Disinfection of ventilators}

Mechanical ventilation is a common means of respiratory support for critically ill patients in the PICU. The use of ventilators and their accessories tends to engender the spread of pathogen carrying droplets or aerosols, which is a high-risk for the transmission of infections in hospitals. Ventilator disinfection is of particular importance for the prevention of hospital infection resulting from the improper use of ventilators (28).

Let's use a Maquet ventilator (Getinge Company, Sweden) as an example. The ventilator's air path is a oneway open-air path, and does not require internal loop disinfection. However, the external circuit of the ventilator is directly connected with the patient's respiratory system, and also the most directly and seriously polluted part. Therefore, for patients who need respiratory support, we use disposable external circuits, including the respiratory pipeline, connecting pipe, humidifier, water collecting cup, and atomizer, and install a disposable filter at the suction and exhalation ends respectively. When the ventilator is in use, we do not replace the loop of the ventilator as regularly as we normally do. This is to prevent the spread of droplets and aerosols in the loop replacing process, and avoid adding to the workload of the medical staff and medical cost. We only replace the loop when there is pollution and mechanical failure, and afterwards it is destroyed as disposable medical waste. The expiratory box is rinsed with hot water $<35^{\circ} \mathrm{C}$ (or $95^{\circ} \mathrm{F}$ ) to remove blood stains or other accumulated organic substances, soaked for 1 hour for disinfection using $75 \%$ alcohol, o-phthalaldehyde solution, or Hexanes G $+\mathrm{R}$, or Yanni's multiple enzyme bactericide cleaner if possible, and dried for $\geq 30$ minutes. The ventilator surface is wiped and disinfected with $75 \%$ medical alcohol. In order to prevent the ventilator screen from being damaged by disinfectant, we use hydrogen peroxide or Jieer wipes to wipe and disinfect the screen and prepare it for the next use. During this pandemic, the hospital's equipment department has been regularly changing the filter screens of the central air supply system of the PICU to ensure the cleanness of the confirmed oxygen and air sources.

\section{Medical waste disposal}

Medical wastes generated in the blue and green areas are disposed of as conventional medical wastes. Wastes generated in the red and yellow areas, including medical and everyday living wastes, are classified, collected, and disinfected following the protocols governing medical wastes in specific places. Before leaving a contaminated area, each packing bag is evenly sprayed with chlorine containing disinfectant (effective chlorine $1,000 \mathrm{mg} / \mathrm{L}$ ) on its surface, or is put into another packing bag so there is an additional layer of protection.

\section{Risk management}

Risk management aims to achieve maximum security utility at minimum cost through the identification, measurement, evaluation, and control of risks (29). In public health emergencies, department managers need to be clear minded and undertake optimal risk management in order to reduce the probability of decision-making errors, prevent losses, and ultimately ensure the safety of medical staff and patients. In this public health emergency, because the risk factors have changed, we should re-evaluate the risk, uncover the weak links in the Department, and minimize safety related incidents. Through repeated evaluation, we found that hospital infection and process errors were the two biggest risk points. The following measures have been implemented to address these risks:

\section{Give full play to hospital infection control supervisors}

Lack of good understanding of the novel coronavirus in the early stage of the outbreak resulted in a high proportion of medical staff becoming infected. A retrospective report from the Zhong Nan Hospital of Wuhan University showed that the infection rate of medical staff was as high as $29 \%$ (30). Another retrospective analysis of 1,099 confirmed COVID-19 cases from 552 hospitals in 31 provinces (diagnostic date as of January 29th) revealed that the infection rate medical staff was $2.09 \%$ (31). There are many high-risk operations in the critical medicine department, including tracheal intubation, tracheotomy, sputum suction, endoscopy, and so on, which may lead to the splashing of blood, body fluids, or secretions, or the formation of aerosols, and medical staff are most likely to be infected at times such as these. If there is not sufficient protection awareness, protective measures are not fully 
implemented, or PPEs are not properly used, the medical staff might get infected themselves, or worse yet, there may be hospital wide infection. Some studies have shown that having full-time supervisors dedicated to infection control can lead to effective and continuous implementation of hospital infection prevention and control measures (32); therefore, full time infection control supervisors play an important role. We have been using health failure mode and effect analysis (HFMEA) to evaluate the risk of in hospital infection during this outbreak, and have been paying particular attention to hand hygiene, cleaning and sterilization, and the aseptic technique. During this pandemic, bearing the identified risk points in mind, the full-time supervisors have been carrying out the following tasks: (I) Supervise hand hygiene practice and correct irregular behaviors, such as not washing hands after operation or incorrect hand washing. (II) Supervise the disinfection and cleaning work, re-check the concentration of the prepared disinfectants, and guide the disinfection work of special areas and special articles. (III) Supervise whether the PPE is worn correctly and whether the steps of donning and doffing isolation clothing are correct during high-risk operations such as tracheal intubation, sputum aspiration, central vein puncture, and so on.

\section{Let the quality control team play an active role}

The department's quality control team is composed of department managers, head nurses, senior doctors, and hospital infection management nurses. The quality control team is responsible for the department's quality control and management, including formulating the plan for continuous improvement of the department's medical service quality and specific implementation measures, regularly analyzing and evaluating the department's service quality, proposing rectification measures for existing problems, and organizing implementation.

During this outbreak, because of the changes to ward layout and work processes, adverse events will inevitably occur if new rules, regulations, or work processes or not implemented. The quality control team assesses risk areas in the workplace, optimizes the process, and formulates SOPs which fit with the department of pediatric critical medicine. It also makes checklists for complex operations such as the donning and doffing of PPE to prevent errors, aggregate and summarize the information from all documents issued by the hospital and formulate training plans accordingly, train personnel in different job positions to become familiar with and competent in their duties in a short time frame, track training results, and improve the working process on a continuous basis.

\section{Conclusions}

This COVID-19 outbreak has been an uncharted challenge for everybody. So far, China has gradually controlled its spread and has been maintaining low case numbers, while the case numbers continue to rise in other countries and regions. Having already experienced all that is currently unfolding abroad, we feel the responsibility to share our experience, and hope this summary of our own practices and insights from our review of some of the literatures can provide some useful references to our colleagues in PICUs both in China and the world over.

Based on these management, we did not see severe patients with 2019-nCoV infection in our department, but our strategy should be updated continuously with accumulated clinical evidence and the increase in knowledge about COVID-19 over time. We hope more guidelines based on the best available evidences and practices from adults and children to better manage critically ill pediatric patients with COVID-19. As the COVID-19 pandemic evolves, implementing the proposed guidelines will help to reduce morbidity and mortality in pediatric patients.

\section{Acknowledgments}

Funding: This work was partially supported by the Natural Science Foundation of Sichuan Province, China (2019YJ0648), and the Scientific Research Foundation of Health Committee of Sichuan, China (18PJ044), XL and WZ obtained the grants.

\section{Footnote}

Conflicts of Interest: All authors have completed the ICMJE uniform disclosure form (available at http://dx.doi. org/10.21037/tp-20-422). The authors have no conflicts of interest to declare.

Ethical Statement: The authors are accountable for all aspects of the work in ensuring that questions related to the accuracy or integrity of any part of the work are appropriately investigated and resolved.

Open Access Statement: This is an Open Access article 
distributed in accordance with the Creative Commons Attribution-NonCommercial-NoDerivs 4.0 International License (CC BY-NC-ND 4.0), which permits the noncommercial replication and distribution of the article with the strict proviso that no changes or edits are made and the original work is properly cited (including links to both the formal publication through the relevant DOI and the license). See: https://creativecommons.org/licenses/by-nc-nd/4.0/.

\section{References}

1. Li Q, Guan XH, Wu P, et al. Early Transmission Dynamics in Wuhan, China, of Novel CoronavirusInfected Pneumonia. N Engl J Med 2020;382:1199-207.

2. Lu H, Stratton CW, Tang YW. Outbreak of pneumonia of unknown etiology in Wuhan, China: The mystery and the miracle. J Med Virol 2020;92:401-2.

3. Wuhan Municipal Health Commission. Report of clustering pneumonia of unknown etiology in Wuhan City. Published December 31, 2019. Accessed January 31, 2020. Available online: http://wjw.wuhan.gov.cn/front/web/ showDetail/2019123108989. Accessed 31 Dec 2019.

4. Johns Hopkins University. COVID-19 Global Cases by the Center for Systems Science and Engineering (CSSE) at Johns Hopkins University. Available online: https:// coronavirus.jhu.edu/map.html. Accessed 21 Apr 2020.

5. Zhu N, Zhang DY, Wang WL, et al. A Novel Coronavirus from Patients with Pneumonia in China, 2019. N Engl J Med 2020;382:727-33.

6. World Health Organization. Naming the coronavirus disease (COVID-19) and the virus that causes it. Available online: https://www.who.int/emergencies/diseases/ novel-coronavirus-2019/technical-guidance/naming-thecoronavirus-disease-(covid-2019)-and-the-virus-thatcauses-it. Accessed 21 Apr 2020.

7. World Health Organization. WHO Director-General's remarks at the media briefing on 2019-nCoV on 11 February 2020. Available online: https://www.who.int/ $\mathrm{dg} /$ speeches/detail/who-director-general-s-remarks-atthe-media-briefing-on-2019-ncov-on-11-february-2020. Accessed 11 Feb 2020.

8. World Health Organization. Modes of transmission of virus causing COVID-19: implications for IPC precaution recommendations. Available online: https://www.who.int/ news-room/commentaries/detail/modes-of-transmissionof-virus-causing-covid-19-implications-for-ipcprecaution-recommendations. Accessed 29 Mar 2020.

9. Swapna T, Andrea Y, Lijia F, et al. Special considerations for the management of COVID-19 pediatric patients in the operating room and pediatric intensive care unit in a tertiary hospital in Singapore. Paediatr Anaesth 2020;30:642-6.

10. Sarman A, Tuncay, S. Principles of approach to suspected or infected patients related Covid-19 in newborn intensive care unit and pediatric intensive care unit. Perspect Psychiatr Care 2020. [Epub ahead of print]

11. Dong Y, Mo X, Hu YB, et al. Epidemiology of COVID-19 Among Children in China. Pediatrics 2020;145:e20200702.

12. Lu X, Zhang $\mathrm{L}$, Du H, et al. SARS-CoV-2 Infection in Children. N Engl J Med 2020;382:1663-5.

13. CDC COVID-19 Response Team. Coronavirus Disease 2019 in Children-United States. MMWR Morb Mortal Wkly Rep 2020;69:422-6.

14. Special Expert Group for Control of the Epidemic of Novel coronavirus Pneumonia of the Chinese Preventive Medicine Association. An update on the epidemiological characteristics of novel coronavirus pneumonia COVID-19. Chin J Epidemiology 2020;41:139-44.

15. Society of Pediatrics, Chinese Medical Association. Recommendations for the diagnosis, prevention and control of the 2019 novel coronavirus infection in children (first interim edition). Zhonghua Er Ke Za Zhi 2020;58:169-74.

16. Ji LN, Chao S, Wang YJ, et al. Clinical features of pediatric patients with COVID-19: a report of two family cluster cases. World J Pediatr 2020;16:267-70.

17. Pediatric group of emergency medicine branch, Chinese Medical Association. Recommendation for emergency procedures of novel coronavirus infection/ pneumonia in children. Chin Pediatric Emergency Med 2020. Available online: https://doi.org/10.3760/cma. j.issn.1673-4912.2020.0004

18. Wang W, Gong LH. Protection behavior of accompanying visitors of hospitalized patients during COVID-19 epidemic period WANG Wei GONG Li-hua. Chin J Infection Control 2020:1-4.

19. Currie, K, Curran E, Strachan E, et al. Temporary suspension of visiting during norovirus outbreaks in NHS Boards and the independent care home sector in Scotland: a cross-sectional survey of practice. J Hosp Infect 2016;92:253-8.

20. Wang ZQ, Zhu ZH, Zhu HW, et al. Psychological Crisis Intervention Model in Xiao tang shan Hospital of PLA. Chin Mental Health J 2003;(09):587-90.

21. Yang HH, Dai L, Chen QX, et al. A qualitative study on the psychological stress of first-line nurses in primary 
hospitals who pneumonia. J nursing Administration 2020;20:1-4.

22. Yu WL, Sun DY. Intervention of mental health risks of female nurses engaged in nursing patients with COVID-19. Occup Health Emerg Rescue 2020;38:106-8.

23. National Hrealth Commission of People's Republic of China. Technical code for disinfection of medical institutions (WS/T 508-2016). Available online: http:// www.nhc.gov.cn/wjw/s9496/201204/54510.shtml. Accessed 17 Apr 2020.

24. National Health Commission of People's Republic of China. A novel coronavirus infection control plan for pneumonia (the 3rd Edition). Available online: http://www. nhc.gov.cn/jkj/s7923/202001/470b128513fe46f086d79667 db9f76a5.shtml. Accessed 28 Jan 2020.

25. National Health Commission of People's Republic of China. Management standard of hospital air purification (WS/T 368-2012). Available online: http://www.nhc.gov. cn/wjw/s9496/201204/54511.shtml. Accessed 17 Apr 2012.

26. National Health Commission of People's Republic of China. Novel coronavirus pneumonia during office and public places Air conditioning and ventilation system operation management guideline. Available online: http:// www.nhc.gov.cn/jkj/s3577/202002/60b58b253bad4a17b96 0a988aae5ed92.shtml. Accessed 12 Feb 2012.

Cite this article as: Zeng P, Luo X, Zeng W, Qiu D, Zhang L, Zhou Q, Wang T, Xiong Z. Strategic management of pediatric intensive care unit in a tertiary children's hospital in southwest China during the COVID-19 pandemic. Transl Pediatr 2020;9(6):849-862. doi: 10.21037/tp-20-422
27. National Health Commission of People's Republic of China. Technical code for disinfection of medical institutions (WS/T 508-2016). Available online: http:// www.nhc.gov.cn/wjw/s9496/201204/54510.shtml. Accessed 17 Apr 2012.

28. Ge HQ, Dai B, Xu PF, et al. Expert consensus on hospitalization prevention for infection during using ventilator in patients with coronavirus disease. Chin J Respiratory Critical Care Med 2020;19:116-9.

29. Li LY, Xu. Risk assessment on healthcare-associated infection management. Chin J Infect Control 2016;15:441-5.

30. Wang D, Hu B, Hu C, et al. Clinical Characteristics of 138 Hospitalized Patients With 2019 Novel CoronavirusInfected Pneumonia in Wuhan, China. JAMA 2020;323:1061-9.

31. Guan WJ, Ni ZY, Hu Y, et al. Clinical Characteristics of Coronavirus Disease 2019 in China. N Engl J Med 2020;382:1708-20.

32. Cai L, Tian YM, Du AP, et al. The role of full-time infection control nurses in the prevention and control of nosocomial infection in Intensive Care Unit. West China Med J 2017;32:901-5.

(English Language Editor: J. Jones) 